\title{
Life Coachers? Padres de alumnos y trabajo de apoyo a la construcción biográfica de los hijos
}

\author{
Life coachers? Parents and the Support Provided for their Children's \\ Biographic Construction
}

Maria Manuel Vieira'

\section{Resumen}

La obligación de asistir a la escuela por un tiempo cada vez más largo transformó la escolarización en un pivote narrativo de las biografías juveniles y en un elemento ineludible del proceso de individuación.

En Portugal, a la entrada de la escuela secundaria, los jóvenes adolescentes son invitados a formular la elección de una carrera entre un conjunto de opciones de la institución. Esta elección, fuertemente anclada en el ejercicio de la autonomía individual y que idealmente deberá implicar al sujeto en un proyecto de vida, constituye un verdadero desafío biográfico -ya sea porque el «campo de posibilidades» depende en gran medida del valor académico demostrado a lo largo de la trayectoria escolar, ya sea porque el contexto de incertidumbre que marca el mundo contemporáneo genera percepciones de riesgo inherentes a cada elección-.

En esa medida, la participación parental en los estudios y el apoyo a la orientación vocacional de los hijos constituye un soporte importante para amortiguar las angustias de la elección. El estímulo y acompañamiento escolar dado por los padres constituye un auténtico «life coaching» de la construcción biográfica de los hijos -aunque se revela también como un proceso difícil e incierto, que puede poner al descubierto los límites de la acción educativa de los padres-.

Teniendo como base empírica entrevistas a padres de alumnos de enseñanza secundaria, en este artículo se analiza la escolarización como un (nuevo) lazo de filiación que vincula a padres e hijos, y se ocupa de esta nueva competencia parental: la participación activa en la biografía escolar de los hijos. Su objetivo es examinar específicamente los desafíos y las ambivalencias del apoyo parental a la elección vocacional de los hijos en un contexto de incertidumbre.

\section{Palabras clave}

Educación, construcción biográfica, padres, niños.

\section{Abstract}

The obligation to attend school for a longer period transformed schooling into a narrative pivot of youth biographies and an inescapable element of the individuation process.

In Portugal, at the entrance to the secondary school, young adolescents are invited to formulate a career choice among a set of options offered by the educational institution. This choice, strongly anchored to the exercise of individual autonomy and ideally involving the individual in a life project, constitutes a true biographic challenge. Either because the «field of possibilities» depends largely on the academic value demonstrated throughout the school trajectory; either because the prevailing context of uncertainty generates perceptions of the inherent risk of each choice.

To that extent, parental involvement in their children's studies and vocational guidance constitutes an important support to cushion the anguish of choice. The encouragement and accompaniment given by parents is a true «life coaching» of the children's biographic construction - although it also reveals a difficult and uncertain process that can expose the limits of the educational action of the parents.

Based on empirical data composed by interviews with parents of young students attending secondary education, this article analyses schooling as a (new) bond of affiliation that links parents and children and deals with this new parental competence: active participation in the children's school biography. Its aim is to examine specifically the challenges and ambivalences of parental support for children's vocational choices in a context of uncertainty.

\section{Keyworks}

Education, biographic construction, parents, children.

1 Instituto de Ciências Sociais, Universidade de Lisboa, mmfonseca@ics.ulisboa.pt. 


\section{Introducción}

La escolaridad obligatoria prolongada constituye una etapa fundamental de la construcción biográfica y el lugar donde se consideran los proyectos de vida.

En el contexto portugués, la educación obligatoria se extiende hoy hasta la finalización de la educación secundaria. En la entrada a este nivel de educación (grado 10), se invita al joven estudiante a elegir una primera opción con implicaciones futuras: o selecciona una elección más académica y generalista (uno de los Cursos Científico-Humanísticos), en el caso de los estudios de nivel superior; o bien opta por una formación más profesional (un Curso de Enseñanza Vocacional o un Curso Profesional), si desea acceder de manera más temprana al mercado de trabajo.

En cualquier caso, la enseñanza secundaria constituye un «momento crítico» de decisión para el adolescente o, en expresión de Giddens, un «fateful moment»: un momento «en que los individuos están llamados a tomar decisiones que tienen consecuencias cruciales para sus pretensiones o, más globalmente, para su vida futura» (Giddens, 1991: 112). Se trata de un período particularmente crítico por el hecho de que el sujeto que está obligado a elegir -el alumno adolescente- se encuentra en un doble proceso de crecimiento y de maduración (Breviglieri, 2007). Esto significa que su identidad (provisional y dudosa) tiene que acomodar una elección (vocacional) que lo compromete con el futuro, lo que constituye un verdadero desafío biográfico. Tanto más cuanto esta proyección en el futuro se realiza en un contexto global de incertidumbre, lo que aumenta la percepción de los riesgos que una determinada elección implica. Ante las dudas que acompañan este proceso, las redes familiares y de sociabilidad asumen particular notoriedad como recurso y soporte para que el joven adolescente pueda lidiar con la incertidumbre de la elección.

En este contexto, los padres son instados a desempeñar una tarea adicional, que se suma al estímulo al estudio y al acompañamiento escolar de los hijos y que, aunque de formas e intensidades variadas, (casi) todos ejercitan como «padres de alumnos»: la de dar apoyo a la orientación vocacional de los hijos. En ciertos casos, este desempeño parental actúa como un auténtico «life coaching»» de la construcción biográfica de los hijos -aunque se puede revelar, también él, como un proceso difícil e incierto.

La relación de las familias con la escuela y, más específicamente, el acompañamiento escolar de los hijos, no constituye un objeto particularmente nuevo en la Sociología. Los enfoques de matriz estructuralista (de inspiración durkheimiana o marxista) o seguidores del «constructivismo estructuralista» (en el sentido de Bourdieu), de orientación más o menos crítica, enfocadas en las grandes tendencias societales, han explicado esta relación a través de una lógica deductiva: de las condiciones objetivas de existencia de los individuos, investigadas a través de un conjunto de indicadores sociales (certificados escolares, profesión, rendimiento, entre otros), se deducen sus prácticas -mediadas o no por el habitus-. En este sentido, las diversas dimensiones de la relación de las familias con la escuela son globalmente explicadas a partir de la mayor o menor familiaridad que ciertos grupos sociales manifiestan con lo que se identifica como cultura escolar. Por su parte, los enfoques de inspiración weberiana, de orientación más relacionada con la acción, han hecho emerger en la sociología (de la educación y de la familia) estudios basados en una lógica más inductiva que permite identificar interacciones educativas diferenciadas en el seno familiar, acopladas (o no) a tipos ideales con prolongaciones en la relación que establecen con la escuela.

\footnotetext{
2 Los expertos del tema indican que el «life coaching» es un proceso relacional y contractualizado entre un sujeto (coachee) y un profesional (coach), con el fin de ayudar al individuo a «aprender a tomar decisiones que generan una vida eficaz, equilibrada y realizada». Las competencias profesionales exhibidas por el especialista (generalmente, con alguna formación en Psicología) consisten en la capacidad de plantear las preguntas correctas y en disponer de las herramientas y de las técnicas más adecuadas para conferir al sujeto el poder para encontrar las respuestas en sí mismo. http://www.lifecoaching.com/pages/life_coaching.html.
} 
Este estudio, anclado en una perspectiva constructivista, que aboga porque «las realidades sociales son aprehendidas como construcciones históricas y cotidianas de los actores sociales y colectivos» (Corcuff, 1995: 22), y el reconocimiento del carácter plural de cada individuo, potenciado en contextos de mayor individualización (Bauman, 2000), pretende abordar una dimensión específica del acompañamiento escolar de los hijos a partir del enfoque de la individuación ${ }^{3}$, captado a través de una perspectiva relacional y procesual: la negociación padres-hijos. El zoom cualitativo sobre la acción en contexto permite entrever otras dimensiones no captadas por los planteamientos antes mencionados: las competencias, pero también las fragilidades de los actores observados, así como sus ambivalencias.

Este artículo ${ }^{4}$ tiene por objeto analizar una dimensión específica de la participación parental en los estudios de los hijos: el apoyo a su elección vocacional. En un primer momento nos referiremos sucintamente a cambios sociales que permiten comprender el surgimiento de un nuevo tipo de relación intergeneracional en el seno familiar y, en ese contexto, la emergencia de la escolarización como un nuevo nexo de filiación que vincula a padres e hijos (Cicchelli, 2001). Después nos dedicaremos a explorar algunas de las ambivalencias parentales en el desempeño del papel de «padres de alumnos». En este caso, en torno a dos pruebas exigidas a sus descendientes: la prueba de madurez y la prueba de autenticidad. Por último, ensayaremos algunas conclusiones provisionales que subrayan una verdadera «competencia» que los padres de alumnos deben exhibir para el éxito de la inversión escolar de los descendientes -la participación activa en la escolaridad de los hijos, en particular el apoyo a la construcción de un proyecto (de futuro); pero también destacar las fragilidades y límites de la acción educativa de los padres-. El material empírico utilizado deriva de datos producidos a partir de un conjunto de entrevistas realizadas a padres de alumnos.

\section{Del método utilizado y de los datos producidos}

El análisis empírico que apoya este artículo se basa en datos cualitativos provenientes de entrevistas individuales realizadas a padres de alumnos de secundaria, producidas en el marco del proyecto «El futuro abierto: incertidumbres y riesgos en las elecciones escolares $\rangle^{5}$, ya concluido (Vieira, 2015). Este proyecto pretendió comprender los procesos (y los protagonistas) involucrados en las elecciones vocacionales que cada joven alumno es invitado a hacer en ciertos momentos de su recorrido académico. Como estas elecciones están deseablemente ancladas a proyectos de vida, constituyen un verdadero desafío biográfico con el que el adolescente tiene que lidiar.

El diseño de investigación involucró el método mixto y una variada batería de técnicas de investigación (análisis documental, encuesta por cuestionario, entrevistas individuales, observación directa). En términos de población a investigar, además del alumnado de enseñanza secundaria, también se contempló profesorado, orientadores escolares y padres de alumnos. El acceso a los padres sufrió múltiples vicisitudes (Vieira, 2017) y, al final, pudimos contar con apenas ocho encuestados -el corpus empírico de este texto-. Son los padres (padre o madre) de los estudiantes que participaron en esta investigación, de tres escuelas secundarias públicas portuguesas situadas en diferentes zonas geográficas -dos zonas distintas de Lisboa (un barrio de clase media y un antiguo barrio obrero) y una pequeña ciudad rural del sur del país-, para garantizar cierta diversidad, en términos de públicos escolares y de ofertas curriculares dispo-

\footnotetext{
3 «Individuación» se refiere al proceso de construcción de una singularidad biográfica (Beck, 1992), mientras que «individualización» se refiere al proceso societario, de larga duración, que ha venido a consagrar al individuo como sujeto.

4 Una versión anterior de este artículo se encuentra publicada en Vieira (2015).

5 Proyecto financiado por la Fundación para la Ciencia y la Tecnología (Proyecto n ${ }^{\circ}$ PTDC/CED/67590/2006), la agencia para la financiación y la evaluación del sistema científico y tecnológico portugués.
} 
nibles. Los entrevistados (6 madres y 2 padres) poseen cualificaciones escolares variadas: dos poseen 9 años de escolaridad; uno completó el décimo año; dos concluyeron el $12^{\circ}$ año; y tres poseen un diploma de enseñanza superior. Sus actividades profesionales se concentran en los servicios (cocinera, propietaria de restaurante, propietaria de café, dueño de pequeña empresa de construcción civil, docente de la enseñanza secundaria y técnica superior de la administración pública), aunque un padre es empresario agrícola y una madre está inactiva.

Su participación voluntaria fue acompañada de información relativa a los objetivos del proyecto y por la cumplimentación de un consentimiento informado. El guión de entrevista contenía temas relativos a la evaluación de la persona del hijo-alumno y de su trayectoria escolar, a las vicisitudes del proceso de elección vocacional y al futuro proyectado, aspiraciones y expectativas.

El contenido de las entrevistas, íntegramente grabadas y transcritas, fue luego sometido a un proceso de análisis de contenido (análisis categorial temático), teniendo en cuenta temas inscritos en el guión de la entrevista, pero también nuevos temas que emergieron del material (Ryan y Bernard, 2000; La Rossa, 2005).

\section{Cambios en las relaciones familiares y escolarización como lazo}

Las relaciones entre generaciones han conocido profundos cambios. En contextos donde la individualización se instala como norma, como sucede en las sociedades democráticas contemporáneas, el reconocimiento del otro, en tanto que merecedor de respeto y sujeto de derechos, se reivindica como principio básico de ciudadanía, cualquiera que sea la edad o el estatuto social.

La profundización en este principio, en particular a lo largo del siglo xx, se ha acompañado de un viraje significativo registrado, de manera concomitante, en el universo de las familias. Sentimentalización, privatización e individualización constituyen los rasgos más marcados de ese viraje. Por un lado, la lógica afectiva en la relación entre los cónyuges se afirma cada vez más como el fundamento exclusivo de la unión, suplantando las consideraciones sociales, morales y patrimoniales que otrora eran factores determinantes en el lazo conyugal. Por su parte, la familia se construye de forma más privada, cerrada sobre sus miembros, liberada de las interferencias exteriores que la marcaban permanentemente en el pasado. Finalmente, la autonomía individual representa un designio colectivo del grupo familiar, que se constituye como soporte de la autorrealización de cada uno de sus miembros.

De esta transformación se deriva un nuevo lugar conferido a los más jóvenes. Fruto del sentimiento que une a los cónyuges, los hijos asumen una nueva centralidad en la familia y son objeto de una elevada inversión afectiva e instrumental por parte de los padres. Las preocupaciones parentales con la protección y el bienestar de cada hijo se inscriben en una nueva representación de la infancia (Ariès, 1973), que consagra en el niño una condición doble y potencialmente ambigua: simultáneamente pequeña, por ser frágil, y grande, por ser respetable como todo ser humano (Singly, 2004: 24).

En efecto, independientemente de su condición de menor, se le atribuye una dignidad idéntica a la del adulto, en lo que representa un notable reposicionamiento -tendencialmente más igualitario- en el conjunto de las relaciones sociales. Ahora bien, este reconocimiento altera los fundamentos de la educación familiar y el ejercicio práctico de la autoridad parental. A un modelo educativo que pretende transformar al niño a través de la imposición de una determinada moral (Singly, 2000a), ejercido autoritariamente por los más viejos sobre los más jóvenes, sucede, como tendencial marco de referencia normativo, un modelo 
educativo que tiene como objetivo el desarrollo autónomo que se basa en el diálogo, la negociación y el establecimiento del contrato como vínculo primordial entre adultos y menores.

Sin embargo, se adivina que semejante cuadro relacional, tendencialmente más democrático, basado en la «similitud», propiciador de un notorio «envolvimiento de proximidad» (Resende, 2008), no deja de suscitar algunas cuestiones. Entre ellas, la que se refiere al lugar de cada interviniente en la relación educativa. Esto porque, «no pudiendo excluir al niño del estatuto de "semejante" que es, por definición, el del individuo democrático, y estableciendo con él una relación basada en la igualdad, ¿cómo construir una "relación educativa" donde, por definición, prevalece una forma de superioridad entre el educador y el educando?» (Almeida, 2005: 589-590).

Más cerca de los hijos que en el pasado y, por eso, más conocedores de las especificidades de cada uno; dotados de algunos saberes periciales en circulación, a veces contradictorios, sobre la mejor forma de apoyar el desarrollo de los más jóvenes; enfrentados al cuestionamiento de los propios hijos y vulnerables a la crítica de otros actores sociales externos a la familia (profesores, médicos, psicólogos, padres de otros alumnos), muchos padres manifiestan sentimientos de incertidumbre en cuanto al sentido de su acción educativa y de angustia en momentos de mayor impasse en la relación parental. Estos sentimientos se extienden a la escolaridad y al desempeño escolar de los hijos, dimensión que en los últimos años adquiere una nueva centralidad en la vida familiar.

En realidad, la escolarización es indisociable de la emergencia del «sentimiento de la infancia» (Ariès, 1973): ella corresponde al designio de protección del niño, un ser frágil que requiere mayores cuidados, proporcionando un tiempo de moratoria educativa antes de acceder a la vida adulta. La intrusión forzada de la escuela en la vida de los niños, primero, y en la de los jóvenes, después, viene a alterar profundamente las rutinas familiares, introducir nuevas prioridades educativas e interferir en los vínculos entre padres e hijos. Por su parte, a medida que se generalizan, los diplomas escolares se transforman en un auténtico pasaporte de inserción profesional (Charlot, 1997), lo que suscita la elevación de las aspiraciones escolares y refuerza el carácter ineludible de la frecuencia escolar. Se puede, pues, afirmar, como bien sugiere Cicchelli (2001), que la escolarización se instituye como nuevo lazo de filiación. Si la ambición genérica de estudios largos para los descendientes refleja una creciente movilización de las familias en torno a la escolaridad de los hijos, el acompañamiento de su vida escolar teniendo en vista el éxito académico representa una implicación efectiva que activa a todos o algunos elementos del grupo doméstico en un trabajo pedagógico inédito. En realidad, la capacidad de intervenir, de inmiscuirse directamente en los asuntos escolares se torna cada vez más un factor decisivo de éxito escolar (Dubet, 1997: 29).

Después de la naturalización de la matriculación escolar (Resende, 2008) de los niños y jóvenes en edad escolar en las últimas décadas, se observa también en la sociedad portuguesa la difusión de una «pedagogización» progresiva del ámbito familiar cotidiano (Vieira, 2011) - o una «escolarización de la existencia», en términos de François Dubet (1997)-. Como se desprende de la investigación sobre las familias y la dinámica familiar en Portugal, «ayudar a sus hijos con las tareas escolares», «llevar a sus hijos a la escuela», «hablar de la escuela y los estudios» (Aboim, 2005: 246), en particular en «fechas de pruebas», «clasificaciones», «profesores», «compañeros de la escuela», «trabajos escolares a realizan», «clases», «materias dadas en la escuela» (Diogo, 2008: 151-152), pasan a ser prácticas comunes (Duarte et al., 2008), congregando a todos o algunos elementos de la familia, especialmente las madres (Wall y Guerreiro, 2005; Diogo, 2008; Perista et al., 2016). Un nuevo tipo de vínculo que, aunque con modalidades e intensidades 
diferentes en cada familia, aproxima y conecta a las generaciones de forma persistente y continuada en el tiempo (Costa, 2016). «Ser padre/madre de alumno» se asume como una nueva dimensión de la responsabilidad parental, tan decisiva como lo es, ahora, la escolaridad en la determinación del futuro de los descendientes.

El éxito escolar representa un elemento central en este vínculo de filiación. Obtener éxito es garantía para la concreción de las ambiciones escolares soñadas por los padres y para el acceso a las «vocaciones» anheladas, por los hijos. Ahora bien, la difusión de la escolaridad desplaza fuera de la familia la tarea de validación de cada uno de sus miembros (Singly, 1997). Es en la escuela donde se realiza ahora el trabajo de calificación (académica y, simultáneamente, identitaria) de los individuos. Este viraje viene a colocar en el propio alumno y en su desempeño individual la responsabilidad por su validación, a través de la obtención de títulos escolares. En ese sentido, como bien resume Singly (1997), cada hijo pasa a ser el sujeto inalienable de su «atesoramiento», aceptando o no jugar el juego escolar.

Así, la generalización de los diplomas y su devaluación relativa producen no solo que la posesión de los mismos resulte cada vez más indispensable, sino que también ponen el desempeño escolar en el centro de tal «atesoramiento». De la calidad de ese desempeño depende en gran medida el valor presente y futuro que cada uno puede alcanzar, lo que no deja de tener repercusiones en el colectivo familiar: el valor social de la familia pasa a medirse (también) por el valor escolar de cada uno de sus miembros (Singly, 2000b). Sin embargo, además de la mera acumulación colectiva de recursos, el desempeño de cada hijo pone igualmente a prueba el valor educativo de los propios padres y, en esa medida, produce y califica su identidad parental. Una trayectoria escolar con éxito representa un motivo de orgullo para los padres y parece demostrar su competencia educativa. Por el contrario, los fracasos constituyen una penosa prueba y se pegan a los progenitores como un anatema sobre su desempeño como educadores.

Es la consolidación de esta norma la que permite entender, en cierta medida, la creciente participación parental en los estudios de los hijos. Aun con los límites que se derivan, tanto de los diferentes recursos académicos exhibidos por las familias o del carácter inalienable del desempeño individual del descendiente, el estímulo y el acompañamiento de los padres a la escolaridad de cada hijo puede revelarse como un apoyo decisivo para que éste supere con éxito las pruebas que ha de enfrentar en su recorrido escolar.

Como se ha dicho, la participación de los padres en la escolaridad de los hijos se desarrolla actualmente en un contexto de mayor proximidad relacional entre las generaciones. Cuando los hijos crecen, se vuelven adolescentes y su autonomía se dilata, expresando un estatuto de alteridad frente a los padres que los aleja del mundo próximo de la infancia (Breviglieri, 2007); la autoridad educativa parental se ejerce, en muchas familias, a través de la intensificación del diálogo y de la negociación con vistas a la obtención de acuerdos. Pero como tales, los acuerdos, basados en el supuesto del respeto por el otro, pueden ser en todo momento denunciables por una de las partes. Lo que no deja de plantear serios desafíos educativos. En el caso de los medios tradicionales de imposición de la autoridad parental -la deserción discrecional como amenaza, la utilización de la violencia física (Vieira, 2011) - queda a los padres la gradualidad (Almeida, 2009) como forma de control parental (sobre la libertad de acción y la circulación otorgada -las «salidas», así como la gestión de los intercambios financieros- el «dinero de bolsillo») y la responsabilización como medio de requerimiento a la acción. De ahí la importancia conferida a una «educación para la responsabilidad» en el abanico de prioridades educativas de muchos padres. El atributo asociado a la adultez, la responsabilidad, presupone que el individuo sea capaz de responder por sus actos y que, por 
ello, sus acciones le sean imputables (Cicchelli, 2001). En lo que concierne a la escolarización, ser responsable significa asumir sus obligaciones de estudiante -es decir, cumplir con éxito su compromiso con los estudios (Cicchelli, 2001)-.

El esfuerzo de los padres en la inversión escolar por parte de los hijos puede, sin embargo, chocar con la amenaza de su potencial logro. En un contexto económico (europeo y nacional) globalmente desfavorable, la difusión de sentimientos de incertidumbre en cuanto al mercado de trabajo y al empleo de jóvenes graduados (Brooks, 2009; Thompson, Russell y Simmons, 2013; Alves et al., 2011) genera dudas y preocupaciones entre los padres. Si los diplomas son hoy indispensables, su colocación en el mercado de trabajo no está garantizada como en el pasado, lo que suscita en estos -quizá más que en los propios hijos- el «miedo a la desclasificación» (Maurin, 2009). Particularmente presente entre las familias que se benefician de mejores estatutos sociales, este «miedo» afecta sin duda el cuestionamiento de los caminos a recorrer y las opciones, en particular escolares, a tomar.

El apoyo a la elección y orientación vocacional de los hijos se vuelve tanto más crucial cuanto el sistema de enseñanza sea más diversificado (Andrade y Ribeiro, 2015) y acentúa, en su interior, el proceso de selección a través de las diferentes vías escolares que ofrece (Bourdieu y Champagne, 1993). La ayuda familiar, más o menos activo, al proceso de elección de los hijos, puede contribuir decisivamente a evitar vías sin salida y posponer el cierre de opciones. En este sentido, la calidad de la participación educativa parental puede constituirse como un ingrediente fundamental de la capacitación del educando -requisito que permite entender, partiendo de la misma posición estructural, las diferentes formas como los individuos moldean sus limitaciones (Martuccelli, 2006)-.

El apoyo a la construcción de la biografía escolar de los hijos se revela, pues, como un dominio particularmente interesante en el estudio de la participación parental en la escolaridad, por él se condensan muchas de las cuestiones arriba planteadas -en cuanto vínculo de filiación, como proceso de negociación, como prueba de responsabilidad parental y como ingrediente de capacitación. A través del análisis de la empiria, veamos con mayor detalle cómo ese apoyo se construye y de qué procesos se sostiene-.

\section{El trabajo de «coaching» biográfico}

En la perspectiva de los padres entrevistados, el futuro se construye cada vez más a partir de la escuela y, para todos, cualquiera que sea la posición social, una escolarización larga representa el medio de alcanzarlo con éxito. Para los padres que aspiran a la movilidad ascendente de sus hijos, la escolarización es un pasaporte para un «futuro mejor» que el suyo. Para padres con estudios superiores, estudiar adquiere el estatuto de evidencia compartida, invocando el crecimiento cognitivo y la preparación profesional que los estudios largos ofrecen como justificación suficiente.

Como vimos, la prolongación de los estudios representa también la prolongación de la escolaridad como lazo de filiación. En las narrativas de los padres entrevistados destaca el hecho de que una parte importante del ámbito familiar cotidiano gira en torno a la escuela, alimentando conversaciones y suscitando acciones, lo que parece contradecir las tesis del despido parental en relación con la escolaridad de los hijos, tan presente en el discurso de algunos docentes y de algunos productores de opinión legitimados por los medios (Melo, 2009).

Este vínculo de filiación asume nuevos contornos a la entrada de la enseñanza secundaria. ¿Qué camino elegir? ¿Proseguir una vía más académica, orientada a la enseñanza superior, o emprender una vía más 
especializada, que permita una inserción profesional más precoz? Después, cualquiera que sea la vía, ¿por qué área/curso concreto optar? Esto no es una tarea fácil. Masificado, el sistema educativo portugués es hoy más diverso, ofreciendo una mayor pluralidad de cursos y rutas distintas dentro del mismo establecimiento escolar. Estructurado en una red densa de opciones conectadas de difícil descifración (Resende y Vieira, 1999) -confiriendo espacios de opciones (disciplinares, por ejemplo) aparentemente similares, pero al final con consecuencias diferenciadas en la continuación de los estudios; que prometen flexibilidad a toda costa (equivalencias y transferencias entre vías), pero que en definitiva presuponen requisitos desiguales para su efectividad- el sistema de enseñanza es hoy también más opaco, lo que exige información redoblada.

La «obligación de elegin» (Beck, 1986 [1992]; Dubet, 2002), con la que el joven está confrontado por el sistema de enseñanza, apela a la exhibición de la «razón instrumental» (Taylor, 2009), o sea, a una cierta ponderación de los medios y la identificación de los fines a alcanzar. El reconocimiento de que el joven puede no estar a la altura de conseguirlo solo, en particular por falta de información, ha hecho proliferar en los últimos años especialistas en el apoyo a la orientación escolar dentro del propio sistema educativo (Dionisio, 2009; 2015). En el conjunto de expertos del «trabajo sobre el otro» (Dubet, 2002) que emergen en la modernidad, es decir, del apoyo a la individuación exitosa, los psicólogos y profesores orientadores desarrollan un trabajo de orientación asistida que involucra, no solo información sobre el sistema escolar, sino también «revelación de los (potenciales) talentos» individuales y, en algunos casos, la orden de la construcción de un proyecto de vida.

Este trabajo, al ofrecer un ingrediente adicional para el apoyo a la orientación, parece ser generalmente valorado por los entrevistados: a excepción de un caso, los demás padres informan que sus hijos disfrutan de un diagnóstico vocacional a la salida de la enseñanza básica. Aunque esta intervención (puntual, en algunos casos, más extendida en el tiempo, en otros), parece que produce casi siempre la confirmación de áreas de interés ya previamente planteadas, el contacto con el orientador escolar puede, sin embargo, plantear también nuevas dudas, desorientación (Dionisio, 2007) y provocar disensiones entre padres e hijos en torno a los caminos a seguir. Tal es el caso relatado por el entrevistado ingeniero agrónomo (entrevista 4), padre de un adolescente poco comprometido con los estudios. Ante el fracaso de una primera opción en Ciencias en la enseñanza secundaria, la orientación profesional se mostró como la solución. Pero el diagnóstico no coincidió con las aspiraciones parentales: la sugerencia de la frecuencia de un curso profesional de Turismo, seductor para el joven, no agradó a los padres, por quedarse por debajo del nivel de estudios ambicionado «[...] creemos que él tiene capacidad para llegar un poco más adelante. [...] que tomara un curso (superior)». Razón por la cual, a regañadientes del hijo, los progenitores se opusieron a esa opción.

Entre lo adecuado y el ambicionado, tanto por los padres, como por los propios hijos, puede existir una distancia considerable, lo que no deja de generar tensiones. Resulta indispensable, sin embargo, elaborar proyectos.

\subsection{Pruebas de madurez: de la «escolaridad despreocupada» a la «escolaridad asumida»}

La generalidad de los entrevistados muestra cierta ambivalencia ante el hecho de que la institución escolar obliga a una elección vocacional al comenzar la enseñanza secundaria.

Por un lado, estos padres consideran que ese momento es muy precoz y que hoy los jóvenes tienen que hacer opciones «demasiado pronto» añadiéndose, de forma próxima, a los argumentos de los hijos y legitimando así las dificultades sentidas por estos. Pero tal absolución de la responsabilidad, 
esta forma de «indulgencia ante el prójimo», como la llama Breviglieri (2007: 34), al ahorrar al hijo adolescente enfrentarse a las pruebas que le permiten afirmarse, lo mantiene rehén de su inmadurez. La prolongación de la edad de la adolescencia resulta una evidencia para los padres, que de esta forma se ven a ellos mismos prolongando su función parental de provisión y cuidado de los hijos, de donde obtienen inequívocas compensaciones afectivas (Machado, 2015). La inmadurez de los hijos sería, pues, el reverso de la medalla de la indulgencia de los padres.

Por otro lado, estos padres ambicionan simultáneamente que los hijos demuestren madurez, para poder establecer con ellos una comunicación más adulta y consagrarles el estatuto de socios en el trabajo educativo que con ellos realizan (Rayou, 2007). En lo que concierne específicamente a la orientación vocacional, para poder escoger un área de estudios es necesario identificar un centro de interés -lo que requiere una definición de sí- y un proyecto -lo que significa una anticipación intencional del futuro (Velho, 1999; Gonçalves, 2008)-. La manifestación de estos requisitos por parte del joven alumno es fundamental en la «negociación de la realidad» (Velho, 1999: 103) con los demás actores -en el caso, con la familia-. Ahora bien, la eventual ausencia de tales requisitos plantea un verdadero problema a los padres. Su participación y apoyo a la elección vocacional de los hijos exige, como contrapartida, la prueba de que estos (ya) no son inmaduros (prueba de madurez).

A la salida de la infancia los adultos (padres y agentes escolares) apelan a la inscripción de los jóvenes en un plan futuro (proyectarse en el tiempo según un objetivo definido y someterse a él) y esperan que éstos se adhieran voluntariamente a esa ordenación, demostrando su madurez. Al comenzar la enseñanza secundaria, algunos jóvenes (mayoritariamente del sexo femenino) parecen estar en disposición de hacerlo, cambiando definitivamente el mundo de la infancia por la explotación de su futuro, abandonando una «escolaridad despreocupada» (que vive en el presente, donde habitan la broma y los desafíos al orden escolar) e invirtiendo en una «escolaridad asumida» (que se refleja en el futuro, responsable y exitosa) (Cicchelli, 2001: 51). Esta opción tranquiliza y es motivo de orgullo para los padres, como confiesa esta profesora con posgrado y madre de dos hijas (entrevista 7), que afirma, sobre la mayor, que ella «no es la mejor de la clase, pero está entre las mejores... fue creciendo en términos de resultados porque ella es muy responsable y hasta madura para la edadi.

Sin embargo, muchos jóvenes encuentran dificultades para adecuar el paso con el calendario de los adultos, mostrando solo ser capaces (o apenas estar disponibles) para definir el futuro en función de lo que están en condiciones de hacer en el presente (Rayou, 2007: 20). Sin abdicar del «ahora», donde se inscribe la experiencia intensa y efervescente de la adolescencia, la proyección en el futuro a que están obligados - como es el caso de la elección de una vía de enseñanza al inicio de la secundaria- tarda en hacerse. La indeterminación, la aleatoriedad y, a veces incluso, el fracaso parecen reinar como forma de respuesta, lo que provoca en los padres una gran ansiedad. La continua apelación de los padres a una mayor responsabilidad y a la adultez puede no surtir efectos inmediatos, lo que provoca en aquellos un penoso sentimiento de impotencia y frustración. En el caso de los dos hijos mayores, este padre (entrevista 4) contrasta la postura responsable de la hija «Madalena sabe lo que quiere, quiere ir a Arquitectura, ya sabe las medias» con la total despreocupación del hijo «iy él [...] quiere alli saber! Es mucho más inmaduro [...] quiere el skate, ordenador y no sé qué... básicamente, él no tiene ningún interés».

Los efectos pretendidos solo pueden surgir después del inesperado enfrentamiento con la experiencia del fracaso escolar, frontera extrema de la «escolaridad despreocupada» que para algunos adolescentes no debería ser traspasada nunca bajo pena de «perder el respeto» -por la invalidación de 
sí mismo que representa-. Esta transformación es relatada por la madre de cuatro hijos, licenciada en Derecho (entrevista 2), a propósito del fracaso escolar sufrido por uno de ellos. Después de que el hijo suspendiera en el $9^{\circ}$ año de escolaridad por asumir actitudes consideradas inmaduras, experiencia que lo habrá marcado profundamente «nunca más fue lo mismo, quedó bastante estigmatizado con aquello... quedó alli un poquito herido...», se operó en él un verdadero cambio, hasta el punto de que la madre reconoce que «repetir ese año tuvo un beneficio inmenso... a partir de abi ya fue responsable y ba sido un niño excelente».

\subsection{Pruebas de autenticidad: ser fiel a su originalidad... pero ajustado a la realidad}

La demostración de madurez no es, sin embargo, la única prueba que el hijo tiene de proporcionar. La prueba de autenticidad deberá acompañarle. La elección de un curso o área de estudio deberá estar asociada a la capacidad de identificación de una singularidad, que permitirá el acierto entre cualidades personales e intransferibles y su traducción escolar. La prueba de si es auténtico significa si es fiel a sí mismo (Taylor, 2009), algo que en la contemporaneidad tiende a convertirse en un verdadero imperativo normativo de existencia. La autenticidad representa, pues, «el ideal moral» que subyace al «individualismo de autorrealización» (Taylor, 2009: 30) que inspira, también, las narrativas parentales a propósito de las opciones escolares realizadas por los hijos. Transversal a todos los padres entrevistados, independientemente de su posición social, está el deseo de que los hijos sean felices a través de su autorrealización. Para ello, se les otorga autonomía para que ellos mismos sean los autores de sus elecciones, como ambiciona la cocinera con el $9^{\circ}$ año de escolaridad y madre de una hija que asiste a la enseñanza secundaria (entrevista 5): «Me gustaba que tenía una idea y que fuera a la idea de ella, ella es que sabe lo que quiere». El mismo deseo es expresado por la propietaria de un pequeño restaurante con el $10^{\circ}$ año de escolaridad (entrevista 6), que confiesa que «نyo no decido nada... quien decide es ella... no es?». La elección puede revelar contornos más académicos «a ella le gustaba más la biología, sin duda», como indica la madre de dos hijas y poseedora del $12^{\circ}$ año de escolaridad (entrevista 1$)$, o menos académicos «él siempre escogió (curso tecnológico de) deporte porque siempre jugó al balón, le encanta jugar al balón...», en las palabras de la madre propietaria de pequeño café con 12 años de estudios (entrevista 8).

Sin embargo, la narrativa de la autonomía y autenticidad concedida a los hijos a veces choca con las ambiciones parentales, cuando las pretensiones de los más jóvenes no se encuadran en el «horizonte de posibilidades» acariciado por los padres. En efecto, como se ha visto anteriormente, la adopción de semejante narrativa no significa la ausencia de una intervención -sutil, no impuesta- en las elecciones y/o en las vías planteadas por los descendientes si éstas se manifiestan demasiado discrepantes con las pretensiones parentales de acceso a un nivel mínimo de escolarización «apropiada».

Por su parte, los criterios que sostienen los proyectos acariciados por los progenitores involucran combinaciones en tensión, no siempre fáciles de alcanzar. Por un lado, los padres manifiestan una ambición de tipo expresivo: la autorrealización de los hijos a través de elecciones «auténticas»; de la otra, revelan una ambición de tipo instrumental: la autonomía financiera que tales elecciones deberán garantizar, como aclara esta madre licenciada (entrevista 2) «... hay que ponderar esos dos factores, hacer cualquier cosa que los haga felices y que les pueda garantizar un nivel de vida con alguna calidad...».

En este caso, proyectos incompatibles se conjugan en una ecuación cuyo desenlace es incierto, dependiendo, entre otros factores, de la capacidad negociadora de ambas partes. La «disuasión dialogante», tarea que puede ser desgastadora y que requiere una inversión activa de los padres, parece ser entonces el modo de orientación más utilizado, en el intento de que los hijos abdiquen de sueños 
irrealistas y converjan en objetivos razonables. Irrealistas por estar por debajo de lo ambicionado «mi bija quiere serpeluquería... es evidente que intentaré que no sea, que sea otra cosa que la realice más...» (Entrevista 2, madre con enseñanza superior). Irrealistas, también, por estar más allá de lo ambicionado, como relata este padre, pequeño constructor civil con el $9^{\circ}$ año de escolaridad (entrevista 3), que confiesa haber quedado «asustado» cuando el hijo, después de frecuentar un curso profesional de informática, llegó a casa con «la conversación que lo que le gustaba mucho era de relaciones públicas...». Ante el escenario de la renuncia al curso actual para abrazar la nueva «vocación», el padre rechazó firmemente esa opción, por significar «andar hacia atrás» en la trayectoria escolar, invitando al renuente hijo a acabar «este [curso] y después pensamos en el resto».

No obstante, las importantes pruebas que los jóvenes tienen que prestar en la enseñanza secundaria a través de las elecciones -la de la madurez y la de la autenticidad-implican la asunción de la escolaridad, es decir, la inversión en una escolaridad exitosa. Así, tener éxito es condición clave para la ampliación de opciones de elección, pudiéndose afirmar que el éxito escolar es (también) orientación. Pero el desarrollo del desempeño a lo largo de la enseñanza secundaria puede también dictar reformulaciones de opciones iniciales. Lo que significa que la elección, lejos de ser un momento, es verdaderamente un proceso.

\section{La construcción biográfica de la persona del alumno y la participación parental: ¿una vigilancia permanente?}

El curso de la escolaridad a lo largo de los tres años de la enseñanza secundaria constituye un tiempo de maduración, reinterpretación y balance de las elecciones provisionalmente realizadas. La pluralidad de pruebas (no solo académicas) que el joven alumno tiene que superar va permitiendo descubrir facetas y probar oportunidades inicialmente no intuidas, que pueden conducir a (nuevas) reformulaciones de las decisiones tomadas: como bien señala Gonçalves (2008: 55), «los proyectos vocacionales no se descubren, sino que se construyen en los contornos de las oportunidades que los contextos histórico-sociales viabilizan o imposibilitan». Al actuar en un contexto institucional que promete cierta flexibilidad de transición entre vías escolares, los alumnos pueden considerar la reversibilidad de las opciones tomadas, siempre que las circunstancias lo aconsejen. Pero raramente lo hacen de forma solitaria. Como se constató, la familia destaca como interlocutor privilegiado en el proceso de elección escolar (Vieira: 2010) y se asume como una «comunidad-de-encaje», «puerto seguro colectivo» contra «incertidumbres a las que se enfrenta individualmente» (Bauman, 2003: 21).

La transición a la enseñanza secundaria inaugura un período particularmente rico e intenso en experiencias: a menudo, el primer año de este nuevo ciclo coincide con el paso a una nueva escuela, el contacto con nuevos colegas y profesores, el enfrentamiento con nuevas exigencias académicas. La forma en que estas pruebas van siendo superadas por el alumno es decisiva en su recorrido ulterior. Y, a pesar de que cada hijo es, como dijimos, el sujeto inalienable de su «atesoramiento» por su desempeño escolar, la verdad es que los padres no quedan ajenos a este proceso. Todos los testimonios, sin excepción, desvendan modalidades de apoyo parental de retaguardia que se pueden revelar decisivos al buen desempeño, tanto como motivadores/incentivadores al trabajo escolar, como amortiguadores (puntuales y/o permanentes) de las incertidumbres y vicisitudes que los hijos experimentan.

En los casos en que la transición transcurra sin problemas, la participación parental se desarrolla de forma mínima (a menudo reducida a incentivos y elogios por las buenas notas obtenidas), entre bastido- 
res de la vida cotidiana familiar, ya que el descendiente demuestra haber asumido, como suya, su obligación como alumno - probando su madurez. Un ejemplo de ello es revelado por una madre entrevistada (entrevista 1), al asumir que la hija «siempre estuvo muy acompañada en la escuela, mucho, mucho...» y que nunca fue necesario obligarla a ir a estudiar «inunca fue preciso.» una vez que ella «ba sido siempre muy responsable, muy responsable, desde pequeñita».

Pero no siempre sucede, lo que obliga a algunos padres a ejercer una intervención más activa. La responsabilidad, exigida a los hijos, de la asunción de su deber de alumno, parece asumir aquí plena reciprocidad cuando el progenitor prueba, a través de su acción, a asumir su deber como educador. Y la acción ejercida puede involucrar la interferencia activa en dos grandes dominios escolares: el que se refiere a la socialización escolar (problemas de orden relacional) y el que se refiere al conocimiento y al aprendizaje (problemas de orden cognitivo).

La transición a un nuevo nivel de enseñanza (y, eventualmente, un nuevo establecimiento escolar) puede traer consigo problemas que no tienen nada que ver con las cualidades académicas de los hijos, pero que pueden tener consecuencias en el desempeño escolar. Son problemas de orden relacional que emergen de episodios desencadenados en el contexto escolar, vividos por las personas como situaciones de injusticia ejercidas sobre su persona. En este caso, la implicación de proximidad que hoy pauta las relaciones intergeneracionales en la generalidad de las familias propicia una atención parental redoblada a los signos de inestabilidad emocional (explícitos o ocultos) emitidos por los hijos. La actuación de los padres (o de uno de los progenitores, en particular) es escogida porque la constatación de la situación en cuestión puede expresarse en la interferencia directa en el espacio escolar a través del ejercicio de la crítica, más o menos intensa, denunciando los episodios de injusticia cometidos, identificando e interpelando a los presuntos agresores (morales) del educando, colocándose al lado de la defensa del descendiente en el reconocimiento de su condición de víctima (Erner, 2006), a quien se debe reparar. Independientemente del nivel de cualificación alcanzado, las denuncias no se hacen esperar. A partir de las entrevistas, captamos dos testimonios ilustrativos. La primera denuncia proviene de una madre que critica a un profesor de la hija por supuestamente «ponerla de lado» reiteradamente, en vez de ayudarla en sus dificultades (entrevistada 5, cocinera con el $9^{\circ}$ año de escolaridad). La segunda denuncia, relatada detalladamente por una madre propietaria de restaurante (entrevista 6), se refiere a una situación crítica ocurrida entre la hija y la dirección de la escuela, por el hecho de que aquélla denunció fallas en el funcionamiento de la escuela en una visita de la Inspección escolar. La reacción negativa e intempestiva de uno de los individuos de la dirección de ese establecimiento de enseñanza le ha causado graves problemas psicológicos solo resueltos después del cambio de escuela.

$\mathrm{Al}$ decidir no abdicar del estatuto de adulto tutelar del educando (menor) que la escolarización refuerza y promueve, el progenitor acaba a menudo por equilibrar, de forma ambivalente, la representación del hijo como ser frágil, que necesita protección ante la amenaza de terceros (lo que justifica la interferencia en su defensa en el espacio público escolar), con la consideración del hijo como un sujeto autónomo, que debe ser responsabilizado por sus acciones (lo que justifica la crítica que le es dirigida en situaciones de desinversión escolar).

En efecto, en el caso en que las vicisitudes experimentadas en el curso del primer año de la educación secundaria son de orden cognitivo, resultantes de un manifiesto desajuste entre la inversión escolar del descendiente y la (nueva) exigencia académica requerida en esta etapa de la escolaridad, emerge con niti- 
dez para el individuo, subrayando la alteridad que lo destaca del Otro - del progenitor y del ideal de hijo deseado-. Convencer al hijo de estudiar choca con la voluntad soberana que éste ejerce por sí mismo en el espacio escolar. De este modo, la autoridad educativa parental resulta claramente limitada en su acción y el recurso a la intensificación del diálogo -el asesoramiento, la amonestación o incluso la ayuda en la búsqueda de soluciones alternativas viables (el cambio de curso, por ejemplo)- representa el único instrumento movilizable, aunque con resultados inciertos. Dos entrevistados, un padre con enseñanza superior y una madre con baja escolaridad, comparten testimonios idénticos de esos límites de la acción parental:

"... la voluntad que ellos prosigan los estudios es, en mucho, nuestra, de los padres... le doy sermones desde hace cuatro o cinco años, desde que él empezó a tener malas notas, después le corre una lágrima al final de la conversación "Voy a mejorar, tienes razón, padre" Pero dura alli muy poco tiempo...». (Entrevista 4).

"Pero yo ya la advertí que ella tiene que estudiar, ¿no? Porque ella tampoco es de estudiar mucho...». (Entrevista 5).

Con el avance progresivo de la escolaridad y la aproximación del final de la educación secundaria emergen nuevas cuestiones que apelan a la (re)activación de la participación parental en la construcción biográfica de los hijos. Es el tiempo de apurar orientaciones, de afinar proyectos y de tomar decisiones más concretas, sobre todo para aquellos que pretenden proseguir los estudios. Frente a un mecanismo de acceso a la educación superior basado en numerus clausus, como el que existe en Portugal, siempre hay un margen más o menos grande de incertidumbre en el resultado de la aplicación, dependiendo de factores variables cada año: el número de candidatos en juego, el número de puestos (limitados) que cada institución ofrece. En este sentido, los alumnos están obligados a elegir (cursos) dentro de la gama de posibilidades conferida por sus clasificaciones académicas.

La duda en cuanto a lo que se pretende específicamente seguir en el futuro se instala entonces en algunos jóvenes. Las entrevistas revelan que el apoyo parental puede ser crucial en ese momento, al ofrecer confianza para una navegación más segura y favorecer así el control sobre la sucesión de pruebas a enfrentar. Este apoyo se expresa de varias maneras y con varias intensidades, pero parte siempre de un conocimiento cercano de la singularidad de cada hijo -que en algunos casos se traduce en un verdadero diagnóstico de personalidad-.

Independientemente de los recursos económicos o culturales disponibles, la simple escucha constante y atenta de las dudas y de las opciones tomadas por los hijos puede resultar una contribución esencial para darles más seguridad en el momento crítico de la elección. En otras palabras, «va de una conversación regular, cotidiana, que siempre tenemos en la perspectiva... no de protegerlo, sino de hacerlo a la vida» como subraya este padre con el $9^{\circ}$ año de escolaridad (Entrevista 3).

Algunos padres, quizá más familiarizados con el universo de la enseñanza superior, llevan más lejos esa tarea de clarificación de caminos de futuro promoviendo, en asociación con la persona, un seguimiento activo en la identificación de vías adecuadas al perfil de cada uno -dentro de los límites de lo aceptable-. Y cuando la desorientación es total, se hace necesaria una intervención más directiva. El relato de esta madre licenciada en Derecho, (entrevista 2), a propósito de su hija, es bien ilustrativo de ello: 
«Por lo tanto, he buscado, sabiendo que ella tenía algunas competencias en términos de gestión, de organización, de comunicación de marketing, busqué mucho los cursos que están en esa área y encontré uno que es un curso de Comunicación Empresarial... tenia todo lo que le gusta: jcomunicación, creatividad, un poco de relaciones públicas... y en fin! Ella acabó por hacer esa opción, está en el último año y está muy satisfecha. Aqui confieso que tuve un papel... "Mira, bija, vi eso ... va al sitio web, ve si te gusta”... porque ella estaba un poquito perdida y tuve que suplir... conociéndola bien...»

Cuando se instala la duda entre varios caminos, propiciar recursos y experiencias de información adicionales podrá ser una ayuda importante en la tarea de explotación desarrollada por los hijos, dando seguridad a sus opciones. Uno de esos recursos se refiere a la previsión del desempeño profesional en el área deseada, cuyo escenario en el contexto profesional real puede ser intuido gracias a la movilización de las redes sociales de que se dispone (los amigos, los compañeros de trabajo), permitiendo a los descendientes confirmar (o informar) su opción, como aclara esta madre con enseñanza superior (entrevista 7): «...por ejemplo, ella hasta llegó a experimentar, como tenemos unos amigos que son médicos [...] habló con un amigo nuestro y fue a asistir a operaciones».

En cuanto a las puertas de las pruebas de acceso, el trabajo de orientación parental puede extenderse a la explotación conjunta de escenarios de entrada en la enseñanza superior, al asesoramiento de estrategias para garantizar el éxito de ese objetivo y la propia desdramatización del proceso, indicando el carácter abierto -siempre reversible- de las elecciones.

Aunque actúa, la acción parental no deja de tener sus límites. Lo hemos subrayado: por un lado, derivan del actual debilitamiento de las promesas de un futuro mejor que en el pasado confería sentido a la inversión escolar; por otro, la acción tropieza con la eventual desinversión del descendiente. En estos casos límite, los padres confiesan su propia impotencia y desaliento ante la llegada al final de la línea, después de agotar los intentos de solución a la ausencia de compromiso escolar de los hijos, como, por ejemplo, se desahoga esta madre (entrevista 8): «En cuanto al futuro, no sé. Además de la edad, que es difícil, ya no sé cómo manejarlo. ¡Ya he agotado las opciones.».

\section{Conclusiones}

Una versión más estructuralista del mundo escolar ha dado prioridad a una concepción de la elección vocacional como una estrategia desarrollada por agentes (especialmente padres, pero también alumnos) cuyo epílogo está deducido desde el principio, a través de la prueba de los grandes números: su concreción inequívoca, de acuerdo con el criterio de los recursos disponibles, dispensando en buena medida el análisis del proceso - un proceso negociador, por lo que no garantizado a priori- y de sus vicisitudes. Nuestro punto de vista se ancla en el reconocimiento de la capacitación de los actores y en la escucha atenta, tanto de sus competencias de acción, como de las fragilidades que encuentran en ese proceso de actuar.

Desde luego, la lente fina propiciada por la metodología cualitativa adoptada (las entrevistas a los padres) permitió identificar que en el seno del mismo grupo familiar - por lo tanto, con idénticos recursos disponibles para potenciar la relación con la escolaridad- ocurren acciones plurales, protagonizadas por cada uno de los descendientes, expresando así su capacidad en la construcción de su singularidad biográfica.

Después, la acción parental revela, también, ambivalencias y vulnerabilidades como «padres-de-alumnos». En realidad, el apoyo parental a la elección vocacional de los hijos se da hoy según principios que se pueden revelar contradictorios. Por un lado, ocurre en el marco de una relación educativa más cercana 
y cada vez más igualitaria entre padres e hijos, pero choca con el hecho de que no todos los hijos tienen (todavía) accedido a la madurez necesaria para asumir la escolaridad (presente) como compromiso y condición de proyección en el futuro. Por otro lado, la elaboración de una elección vocacional requiere del joven una prueba de autenticidad, prueba esa acariciada por los propios padres. No obstante, esa búsqueda de sí se realiza en un tiempo en que el adolescente está construyendo una identidad aún provisional lo que puede desembocar en la manifestación de autenticidades «irrealistas» - en la perspectiva de los padres-.

Finalmente, por mucho que la competencia parental de orientación sea ejercida de forma activa, es en la escuela donde se realiza la validación del descendiente lo que, en casos extremos de desinterés escolar reiterado, pone al descubierto las vulnerabilidades y los límites de la acción parental. No obstante, incluso en situaciones límite y a pesar de las dificultades a las que se enfrentan, ningún padre parece estar dispuesto a abdicar de este trabajo de auténtico «life coaching» que pretende ayudar a cada hijo a tomar decisiones (de futuro).

\section{Referencias bibliográficas}

Aboim, Sofia (2005): "Dinâmicas de interacção e tipos de conjugalidade" en Karin Wall (org.): Famílias em Portugal. Lisboa: Imprensa de Ciências Sociais.

Almeida, Ana Nunes de (2005): “O que as famílias fazem à escola... pistas para um debate”. Análise Social, XL (176), 579-593.

Almeida, Lia (2009). Juventude, Família e Autonomia: Entre a Norma Social e os Processos de Individuação. Tese de doutoramento em Sociologia. Lisboa: Universidade de Lisboa.

Alves, Nuno Almeida; Cantante, Frederico; Baptista, Inês y Carmo, Renato Miguel (2011). Jovens em transiçôes precárias. Trabalho, quotidiano e futuro. Lisboa: Mundos Sociais.

Andrade, Ana Bela y Ribeiro, Ana Maria (2015): "Itinerários formativos. Possibilidades e limites no ensino secundário” en Maria Manuel Vieira (coord.): O futuro em aberto. Lisboa: Editora Mundos Sociais.

Ariès, Philippe (1973). L’Enfant et la Vie Familiale sous l'Ancien Régime. Paris: Editions du Seuil.

Bauman, Zygmunt (2003). Comunidade: A Busca por Segurança no Mundo Atual. Rio de Janeiro: Jorge Zahar Editor.

Bauman, Zygmunt (2000). Liquid modernity. Oxford: Polity Press.

Beck, Ulrich (1986). Risk society: Towards a New Modernity. London : Sage Publications, 1992.

Bourdieu, Pierre y Champagne, Patrick (1993): “Les exclus de l'intérieur" en Pierre Bourdieu (dir.): La misère du monde. Paris: Éditions du Seuil.

Breviglieri, Marc (2007): “Ouvrir le monde en personne: Une anthropologie des adolescences” en Marc Breviglieri y Vicenzo Cicchelli (orgs.): Adolescences Méditerranéennes: L’Espace Public à Petits Pas. Paris: L'Harmattan.

Brooks, Rachel (ed.) (2009). Transitions from Education to Work: New Perspectives from Europe and Beyond. Hampshire: Palgrave Macmillan.

Corcuff, Philippe (1995). Les nouvelles sociologies. La réalité sociale en construction. Paris: Éditions Nathan. 
Costa, Ana Paula (2016): "Relação famílias-escola. Ações e representações" en Teresa Seabra y Pedro Abrantes (org.): Incursões na sociedade educativa. Lisboa: Mundos Sociais.

Charlot, Bernard (1997): "Pour le savoir, contre la stratégie" en François Dubet (dir.): Ecole, Familles, le Malentendu. Paris: Textuel.

Cicchelli, Vincenzo (2001). La Construction de l'Autonomie: Parents et Jeunes Adultes Face aux Etudes. Paris: Presses Universitaires de France.

Diogo, Ana Matias (2008). Investimento das Famílias na Escola: Dinâmicas Familiares e Contexto Escolar Local. Oeiras: Celta Editora.

Dionísio, Bruno (2015): "O que os orientadores fazem com os alunos? O trabalho de preparação das competências para uma carreira de escolhas” en Maria Manuel Vieira (coord.) (2015): O futuro em aberto. Lisboa: Editora Mundos Sociais.

Dionísio, Bruno (2009). A Orientação no Plural: Promessas e Limites do Serviço Público de Orientação Escolar. Tese de doutoramento em Sociologia. Lisboa: Universidade Nova de Lisboa.

Dionísio, Bruno (2007): “O psicólogo na escola e a escola no psicólogo: interrogações preliminares de um tema de pesquisa” en Maria Manuel Vieira (org.): Escola, Jovens e Media. Lisboa: Imprensa de Ciências Sociais.

Duarte, M. Isabel (coord.); Roldão, Cristina; Nóvoas, David; Fernandes, Susana y Duarte, Teresa (2008). Estudantes à Entrada do Secundário. Lisboa: GEPE/Ministério da Educação.

Dubet, François (1997): “Ecole, familles, le malentendu” en François Dubet (dir.): Ecole, Familles, le Malentendu. Paris: Textuel.

Dubet, François (2002). Le Déclin de l'Institution. Paris: Editions du Seuil.

Erner, Guillaume (2006). La Société des Victimes. Paris: Editions La Découverte.

Giddens, Anthony (1994). Modernidade e Identidade Pessoal. Oeiras: Celta Editora.

Gonçalves, Carlos Manuel (2008). Pais Aflitos, Filhos com Futuro Incerto? Um Estudo sobre a Influência das Familias na Orientação dos Filhos. Lisboa: Fundação Calouste Gulbenkian/Fundação para a Ciência e a Tecnologia.

La Rossa, Ralph (2005): “Grounded Theory Methods and Qualitative Family Research”. Journal of Marriage and Family, 67 (4), 837-857.

Machado, Maria do Céu (2015). Adolescentes. Lisboa: Fundação Francisco Manuel dos Santos.

Martuccelli, Danilo (2006). Forgé par l'Epreuve: L’Individu dans la France Contemporaine. Paris: Armand Colin.

Maurin, Eric (2009). La Peur du Déclassement. Une Sociologie des Récessions. Paris: Editions du Seuil.

Melo, Benedita Portugal e (2009). Os Professores do Ensino Secundário e os Rankings Escolares. Vila Nova de Gaia: Fundação Manuel Leão.

Perista, Heloísa; Cardoso, Ana; Brázia, Ana; Abrantes, Manuel; Perista, Pedro y Quintal, Eudelina (2016). Os usos do tempo de homens e de mulheres em Portugal. Lisboa: Comissão para a Igualdade no Trabalho e no Emprego. 
Rayou, Philippe (2007): “De proche en proche, les compétences politiques des jeunes scolarisés". Education et Sociétés, 19 (1), 15-32.

Resende, José M. y Vieira, Maria Manuel (1999): “As encruzilhadas da escolarização secundária no limiar do século XXI”. Colóquio - Educação e Sociedade, 5 (nova série), 187-218.

Resende, José M. (2008). A Sociedade contra a Escola? A Socialização Politica Escolar Num Contexto de Incerteza. Lisboa: Instituto Piaget.

Ryan, Gerry W. y Bernard, H. Russell (2000): "Data Management and Analysis Methods” en Dezin, Norman K. y Lincoln, Yvonna S. (eds): Handbook of Qualitative Research, $2^{\text {nd }}$ ed. Thousand Oaks, CA: Sage Publications.

Singly, François de (2004): "Le statut de l'enfant dans la famille contemporaine" en François de Singly (org.): Enfants -Adultes: Vers Une Egalité de Status? Paris: Universalis.

Singly, François de (2000a). O Eu, o Casal e a Família. Lisboa: Publicações Dom Quixote.

Singly, François de (2000b): “L'école et la famille” en Agnès van Zanten (dir.): L'Ecole: L'Etat des Savoirs. Paris: Editions La Découverte.

Singly, François de (1997): "La mobilisation familiale pour le capital scolaire" en François Dubet (dir.): Ecole, Familles, le Malentendu. Paris: Textuel.

Taylor, Charles (2009). A Ética da Autenticidade. Lisboa: Edições 70.

Thompson, Rachel; Russell, Lisa y Simmons, Robin (2013): “Space, place and social exclusion: an ethnographic study of young people outside education and employment". Journal of Youth Studies, 17 (1), 63-78.

Velho, Gilberto (1999). Projeto e Metamorfose: Antropologia das Sociedades Complexas. Rio de Janeiro: Jorge Zahar Editor.

Vieira, Maria Manuel (2017): “Efeitos metodológicos da capacitação adolescente: questionamentos críticos a propósito de uma pesquisa em espaço escolar” en José Manuel Resende y Alexandre Martins (coord.): (Con)Vivemos numa Sociedade Justa e Decente? Críticas, Envolvimentos e Transformacõos. Porto: Fronteira do Caos.

Vieira, Maria Manuel (coord.) (2015). O futuro em aberto. Lisboa: Editora Mundos Sociais.

Vieira, Maria Manuel (2011): “Aprendizagens, escola e a pedagogização do quotidiano” en Ana Nunes de Almeida (coord.): História da Vida Privada em Portugal: Os Nossos Dias, vol. 4. Lisboa: Círculo de Leitores/Temas e Debates.

Vieira, Maria Manuel (2010): "Incerteza e individuação: escolarização como processo de construção biográfica". Sociologia, Revista do Departamento de Sociologia da FLUP, vol. XX, 265-280.

Wall, Karin y Maria das Dores Guerreiro (2005): “A divisão familiar do trabalho” en Karin Wall (org.): Famílias em Portugal. Lisboa: Imprensa de Ciências Sociais. 


\section{Nota biográfica}

Maria Manuel Vieira nació en Lisboa. Después de la licenciatura en Sociología (ISCTE, 1982), trabajó en el Gabinete de Estudios y Planificación del ME (1982-1984) integrada en un proyecto coordinado por el IIPE (París). Profesora en el Departamento de Educación de la Facultad de Ciencias de Lisboa (19842003) y miembro del Centro de Investigación en Educación (FCUL). Investigadora del Instituto de Ciencias Sociales de la Universidad de Lisboa desde 2003, es el coordinadora del Observatório Permanente da Juventude, que integra la coordinación científica del Observatório dos Percursos dos Estudantes, en el Rectorado de la Universidad de Lisboa.

Doctora en Sociología (1998, ISCTE, Lisboa) con una tesis publicada bajo el título La educación de los herederos. Las prácticas educativas de la clase dominante de Lisboa en las últimas décadas (Fundación Calouste Gulbenkian, 2003). Ha integrado y coordinado varios proyectos de investigación nacionales e internacionales. Sus actuales intereses de investigación se sitúan en el ámbito de la Educación, en particular en los siguientes ámbitos: sistema educativo y modernidad, escolarización y procesos de individuación, escolaridad como lazo de filiación entre padres e hijos, culturas adolescentes en el espacio escolar. Autora de varios libros, colecciones y artículos científicos, integra actualmente los proyectos Insuficiencia y abandono escolar en UL: escenarios y recorridos, y Escuelas que hacen mejor: el éxito escolar de los descendientes de inmigrantes en la escuela pública, financiados por la FCT. 